
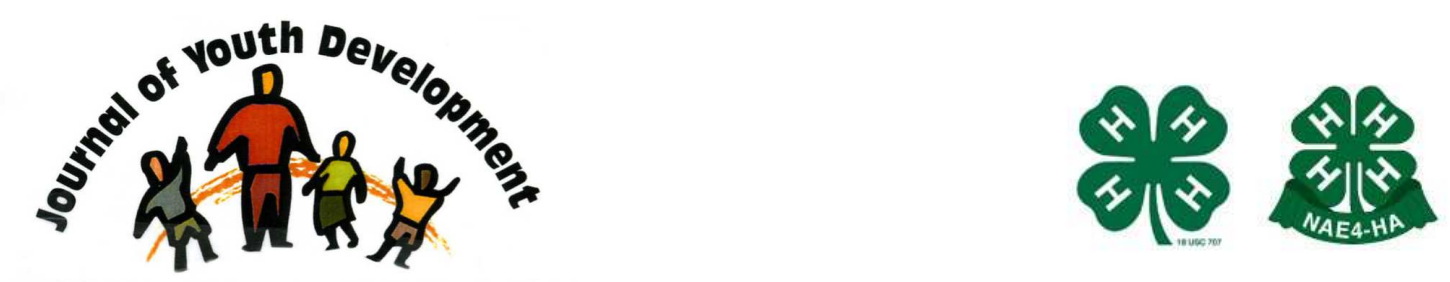

Bridging Research \& Practice

\title{
Addressing Criteria in the Development of a New 4-H Foods Project
}

\author{
Susan McConnell \\ Department of $\mathrm{Ag}$ \& Extension Education \\ Penn State University \\ University Park, PA \\ SLM5004@psu.edu \\ Jan Scholl \\ Department of $\mathrm{Ag}$ \& Extension Education \\ Penn State University \\ University Park, PA \\ jscholl@psu.edu
}




\title{
JOURNAL OF YOUTH DEVELOPMENT \\ bridging research and practice

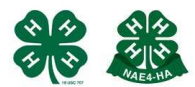

Volume 5, Number 3, Fall 2010

Article100503PA001

\section{Addressing Criteria in the Development of a New 4-H Foods Project}

\author{
Susan McConnell and Jan Scholl \\ Penn State University
}

\begin{abstract}
As youth and society changes, 4- $\mathrm{H}$ projects must change and adapt. Make it with Mixes, a 4-H curriculum, provides a new way of looking at food preparation. It may be one of the first state foods projects created without an emphasis on "from scratch" cooking or baking. Aimed at beginning 4-H members, ages 9 to 13, the project teaches cooking skills with the aid of commercial mixes. However, the main focus of the project is on making comparisons between food labels, costs per serving, and recognizing quality food products. Science and mathematics activities are also incorporated into the curriculum. This article discusses the organization, criteria and strategies used to create this new foods project.
\end{abstract}

\section{Project Overview}

Since 1914, and perhaps even earlier, 4-H has taught cooking and baking "from scratch." In 2006, a 4-H club decided to try an activity using commercial mixes. Following the activity they communicated what they had learned in a fair exhibit: The club members enjoyed the mix project because it saved time. They found it was easier to learn food preparation skills when the number of ingredients and equipment was reduced. The 4- $\mathrm{H}$ leaders said that it made a good club project and youth with a lot of experience enjoyed it as much as the beginners. The young people could also compare nutrition information using the labels on the packages. New experiences with equipment was put into productive activities: such as kitchen scissors as a means to open packages (and cut small foods and pizza) and an oven thermometer used to make a determination whether to adjust baking times or oven rack settings to meet the requirements of the package recommendations.

For many years, using criteria as basis of curriculum development and evaluation has been shown to create highly effective educational materials and programs (Defazio, 2008; Denemark, 1963; Gordon, 1968; Jacobs, 1989; Hass \& Parkay, 1993; McNeil \& Darby, 2008; Squires, 2005; Wiggins \& McTighe, 2006). Other than for the Expanded Foods and Nutrition Education 
Program (known as EFNEP), only a few (Armstrong \& Vasold, 1925; Brink, 1964; Futchey \& Bishop, 1941; Ikeda \& Moyles, 1986) have studied 4-H foods projects during their project development phase.

\section{Objective for the Project Development}

The main objective of this study was to develop a basic state level 4-H foods project (using criteria established by a curriculum committee) to help young people learn basic concepts of food preparation, with fewer ingredients and equipment.

\section{Method}

In 2007, the 4-H Family and Consumer Sciences state committee met and determined that a mix project would be useful to younger 4-H members ( 9 to 13 years of age) based on the work completed by the $4-\mathrm{H}$ members in 2006 . But, Extension educators and volunteer leaders in the state were unsure if the mix project would be successful. Would the fair judges confuse the products made with mixes with recipes from scratch? Would a separate fair category designed specifically for the mix products need to be created?

\section{Criteria}

Criteria, established by the project development committee, were used to create the project. It was important that criteria be selected that would address preparation of commercial mixes as well as basic meal management skills. These were the fourteen criteria selected:

1. Compare Nutrition Facts labels and judge food products

2. Encourage foods demonstrations

3. Teach food and kitchen safety

4. Illustrate basic table setting

5. Describe how to do the dishes

6. Explain math and science concepts

7. Incorporate diversity messages

8. Include some recipes to enhance the taste of the commercial mixes

9. Develop enthusiasm among young members and volunteer leaders

10. Emphasize cooking and baking skills not currently found in cookbooks

11. 4-H volunteer leaders as well as teachers should be able to lead the project.

12. Alternative recipes for low-income audiences not able to afford the commercial mixes

13. Appeal to older 4-H members and those who would like to continue in the project

14. A project record that is easy to complete, allows youth to see what they learned, and helps volunteer leaders and Extension professionals evaluate how well the project teaches basic food preparation skills.

In addition to the creation of the $4-\mathrm{H}$ project guide, $4-\mathrm{H}$ leaders felt that an overall food series leader guide (previously produced on videotape) needed to be updated on DVD to include educational resources to successfully complete the new project. 


\section{Funding and the Review of Materials}

In 2008, a General Mills grant was secured to create a Make it with Mixes project on the state level. The grant required that a registered dietician work on the project. The main authors (4- $\mathrm{H}$ curriculum specialist and Extension educator) and the editor were employed by Cooperative Extension. A computer technician and an illustrator were hired. Over 50 commercial mixes were purchased and entire mix boxes were reviewed for recipes, hints, and ingredients used. Some of the mixes were gluten-free, fat-free or made a nutrition claim. The mixes and the recipes were evaluated using product standardization evaluations from various sources.

To introduce 4- $\mathrm{H}$ leaders and members to the project, five leader in-services were held. 4- $\mathrm{H}$ members made mixes and demonstrated them during these in-services, not only to test the mixes and their suitability to young people, but also to gain support and comments from the leaders and members who attended throughout the development process. Each of the inservices meetings were evaluated with the standard participant evaluation forms used in our state. Extension agents also received training and were able to pre-order the project materials at the trainings.

Three sets of reviews were sent out to all foods leaders and Extension educators. The last set of reviews was distributed and collected during an Extension annual conference as a quick turnaround was necessary before the project could be edited at the university level. (In this case, the leaders and educators evaluated the curricula by writing comments on the drafts.) The three periods of review were important due to the diversity of the comments and the challenge of addressing the criteria. Four meetings with the illustrator were needed in order to create the eighty graphic images in the forty page project.

\section{Curriculum Development Preliminaries}

The authors first selected the types of mixes that were to be addressed in the project and the order that they were to appear in the project. Designed to build skills developmentally and focus instruction on similar types of baking pans and equipment, the order of mixes presented in the project was as follows: puddings, cake, quick breads and pound (loaf) cakes, muffins, wedges and bars (corn bread, gingerbread, bar cookies), cookies, biscuits, pizza and pie crust and pancake and waffle mixes. Because there are many other mixes available, the option to use those mixes was supported. Members were required to make as few as two different mixes of the same type (i.e. brand name vs. generic) per year or complete the entire project book of ten types of mixes. Ideas were given on how to use the mix in creative ways, for example, layering a pudding parfait.

\section{Addressing the Criteria in Developing the Project:}

The following criteria were used in developing the curriculum:

\section{Compare Nutrition Facts labels and judge food products.}

Outside of a computer review of every ingredient, it is difficult for adults and youth to determine nutritive value of recipes. Reviewing and comparing nutrition facts labels found on commercial products is much easier. In the project, two nutrition facts label "blanks" were included for every mix type so members could fill them in using the package information and make the comparisons. In addition, a form to compare cost per serving and a food product evaluation specific to the type of mix helped the youth determine how a standardize food product should look and taste 


\section{Encourage foods demonstrations.}

An entire page of the curriculum was dedicated to food demonstrations and a place was designated in order to brainstorm possible topics to present to their group. A state 4-H food presentations resource was also suggested.

\section{Teach food and kitchen safety.}

Five main hazards in the kitchen were addressed: cuts, burns, falls, electric shock, and explosion (food from microwave cooking and glass put on the burners). The importance of washing hands, setting up the kitchen counter for food preparation, putting a damp cloth under bowls to prevent breakage, and returning food to the refrigerator before washing the dishes were among the topics related to food and kitchen safety.

\section{Illustrate basic table setting.}

An entire page was dedicated to setting the table with two large illustrations on how to set place settings for a basic dinner and a basic dessert setting (that does not include a knife). Other more complex table settings were illustrated in the first drafts, but it was thought that only basic settings should be included in this project; the more complicated relegated to an advanced foods or an etiquette project.

\section{Describe how to do the dishes.}

Step-by-step instructions were given on how to wash dishes in a sink and in a dishwasher. An illustration showed how to set up a kitchen counter in order to have the food preparation go smoothly and safely with areas for: dishwashing, food waste, and cooling the food product after baking.

\section{Explain math and science concepts.}

Math and sciences concepts were shared in sections related to: measurements, sifting, greasing and flouring, cooling, pan sizes, mixing and over-mixing, the difference between baking soda and baking powder, and the cutting of servings from round cake and rectangular pans.

\section{Incorporate diversity messages.}

Most of the illustrations were line drawings of equipment and food. The few illustrations with human figures represented both boys and girls of various races. Many options were included for the types of foods the 4-H member could make. Cultural foods could be adapted easily using a mix as a basic ingredient. Gluten-free mixes for those with celiac disease and other mixes without egg, salt or other ingredients were addressed for those with food allergies. An affirmative action statement was also included. Members without sight can request an audio version of the project.

\section{Include some recipes to enhance the taste of the commercial mixes}

Additional recipes were added to supplement the mix project, such as crumb topping for pies and muffins, making pound cake from cake mix, and a single pudding serving for a snack.

\section{Develop enthusiasm among young members and volunteer leaders.}

During the training the leaders were impressed by the quantity of food preparation techniques that were built into the project. The young people demonstrating at the leaders in-services were also a major influence in generating enthusiasm. Each shared how they used the mixes to prepare foods for their families and also as afternoon snacks. 
10. Emphasize cooking and baking skills not currently found in cookbooks. The following skills were not found in current cookbooks or in our current food and nutrition series, but were included in this project: Use of oven thermometers and kitchen scissors, pan sizes, type, how to cool food products and test for doneness, and graphics of what happens when something is over mixed.

11. 4-H volunteer leaders as well as teachers should be able to lead the project. The text was large enough for beginning members to read. Sections on the inside front cover for the volunteer leader or teacher discussed the objectives of the project, completion requirements, possible food allergies of young people and useful kitchen equipment. Short sentences described individual steps. Through illustrations, leaders and professional teachers were able to describe and demonstrate the food preparation skills to young people.

\section{Alternatives recipes for low-income audiences not able to afford the commercial mixes.}

A recipe for master mix and other alternative projects (making a cookie mix in a jar, for example) were given.

\section{Appeal to older 4-H members and those who would like to continue in the project.}

The member may compare just two mixes or many more. Young people can select mixes not included in the project and many alternative activities were suggested.

\section{A project record that is easy to complete, allows youth to see what they learned, and helps volunteer leaders/teachers and Extension professionals evaluate how well the project teaches basic food preparation skills.}

The project record includes a few lines of writing, but most of the record was created with checkmarks indicating when the young person completed the skills and when they had practiced enough to do them well.

\section{Evaluation of the Reviews}

Notes were taken during the development process on any difficulties the youth, volunteer leaders or extension educators expressed during the in-service trainings. The leaders wanted simple rating scales (good, fair and poor) for each food product evaluation.

Some disagreed on how children should be taught various skills (cracking an egg) and there were many concerns about the fair exhibits. The developers had a difficult time communicating how the illustrations should look and either had to demonstrate them for the illustrator or find examples that would communicate the ideas discussed in the text.

\section{In-service Evaluations}

At the in-services, youth demonstrated making a mix and general instruction was given about the project book. The leaders were very excited when the youth were present. They appreciated that the project book was created based on the criteria outlined by other leaders and that the leader guide DVD was updated soon afterward. Most were amazed at the quantity of food preparation skills and advice given in the mix project. 
The only negative comment expressed was that the recipes made from the master mix should have been included even though they were available on-line or in Expanded Food and Nutrition Education (EFNEP) materials.

\section{Impact}

The project was completed and forty-six out of sixty-seven counties in the state pre-ordered materials including more than 2,500 project books for use in their counties. Additional materials were developed related to etiquette and master mixes recipes were placed on the web-site. One leader's guide DVD was sent to each county with the option of ordering more and/or making their own copies.

The requirements were found acceptable and exhibits were included in the fair premium listings on the county and state level. Requests were made for presentations from community groups. Fifty Family and Consumer Science educators from across the country attended an informational session about the project in Portland, ME during the annual NEAFCS conference in the Fall 2010 and have started ordering materials for their state.

The 4- $\mathrm{H}$ members currently taking the project range in age from beginning 4- $\mathrm{H}$ youth (8 years old) to older and more experienced $4-\mathrm{H}$ members, 16 years of age or older. Though the project has not reach an entire completion cycle with exhibits at the fair, preliminary data show that the young people are increasing their learning in important areas which had not before been addressed in other foods projects: label reading and comparison, food product knowledge and improvement, dishwashing, portion sizes, and showing creativity in their efforts.

\section{Conclusion}

The main objective of this study was to develop a basic state level 4-H foods project (using criteria established by a curriculum committee) to help young people learn basic concepts of food preparation, with fewer ingredients and equipment. The development of this project was built on criteria and input by leaders, members and extension educators through testing, several reviews and pre-and post in-service evaluations. A separate category of fair exhibits was created. After completion of the 4-H "Make it with Mixes" curricula, the authors determined that criteria were useful in the development and the acceptance of the materials, especially when the project was controversial in its approach to learning foods and nutrition concepts (mix preparation vs. "from scratch" baking).

This project would be easily adapted in most states or counties and would be very useful in family and consumer science classrooms and afterschool programs where time is limited for instruction.

The project materials may be ordered from Publications Distribution, College of Agricultural Sciences, University Park, PA 16802. Call 877-345-0691 for cost, shipping and quantity orders.

Scholl, J., Kralj, R., Fuller, R., \& Jankowski, B. (2010). Make it with Mixes, University Park, PA: Penn State University Extension Publication J0671A. 
The DVD leader guide may be ordered from the Department of Agricultural and Extension Education, \% Jan Scholl, 2B Ferguson Building, University Park, PA, 814-863-7444.

Questions about the curricula may be addressed to: jscholl@psu.edu.

\section{References}

Armstrong, G., \& Vasold, N. (1925). The organization and direction of girls' $4-H$ clubs in food projects. University of Illinois Experiment Station Bulletin 300, 18 pp.

Brink, M. (1964). A preliminary appraisal of the 4-H project, Exploring Foods and Nutrition. Masters of Science thesis, Michigan State University.

Defazio, J. (2008). Designing with precedent: A cross-disciplinary inquiry into the design process. Ph.D. dissertation, Indiana University.

Denemark, G. (1963). Criteria for curriculum decisions in teacher education: A report. Washington, DC: Association for Supervision and Curriculum Development.

Futchey, F., \& Bishop, T. (1941). A study of the educational growth of 4-H food preservation club members-Massachusetts. USDA Extension Circular, 356, 24 pp.

Gordon, I. (1968). Criteria for theories of instruction. Washington, DC: Association for Supervision and Curriculum Development.

Hass, G., \& Parkay, F. (1993, Sixth Ed.). Curriculum planning: A new approach. Boston: Allyn and Bacon.

Ikeda, J., \& Moyles, W. (1986). A survey of 4-H foods and nutrition leaders. Paper, University of California, $10 \mathrm{pp}$.

Jacobs, H. (1989). Interdisciplinary curriculum: Design and implementation. Alexandria, VA: Association for Supervision and Curriculum Development.

McNeil, J., \& Darby, J. (2008, Seventh Ed.). Contemporary curriculum: In thought and action. Hoboken, N. J.: Wiley.

Scholl, J., Kralj, R., Fuller, R., \& Jankowski, B. (2010). Make it with Mixes, University Park, PA: Penn State University Extension Publication J0671A.

Squires, D. (2005). Aligning and balancing the standards-based curriculum. Thousand Oaks, CA: Corwin Press.

Wiggins, G., \& McTighe, J. (2006, Expanded Second Ed.). Understanding by design. Upper Saddle River, N. J.: Pearson Education.

(c) Copyright of Journal of Youth Development $\sim$ Bridging Research and Practice. Content may not be copied or emailed to multiple sites or posted to a listserv without copyright holder's express written permission. However, users may print, download or email articles for individual use. 